\title{
Les arts en France autour de 1400. Création artistique, questions iconographiques
}

\section{Daniel Russo}

\section{Q OpenEdition}

1 Journals

Édition électronique

URL : https://journals.openedition.org/cem/707

DOI : $10.4000 /$ cem.707

ISSN : 1954-3093

\section{Éditeur}

Centre d'études médiévales Saint-Germain d'Auxerre

\section{Édition imprimée}

Date de publication : 15 août 2005

ISSN : 1623-5770

\section{Référence électronique}

Daniel Russo, "Les arts en France autour de 1400. Création artistique, questions iconographiques », Bulletin du centre d'études médiévales d'Auxerre | BUCEMA [En ligne], 9 | 2005, mis en ligne le 25 octobre 2006, consulté le 22 septembre 2022. URL : http://journals.openedition.org/cem/707 ; DOI : https:// doi.org/10.4000/cem.707

Ce document a été généré automatiquement le 22 septembre 2022.

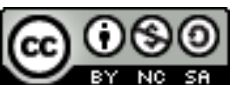

Creative Commons - Attribution - Pas d'Utilisation Commerciale - Partage dans les Mêmes Conditions 4.0 International - CC BY-NC-SA 4.0

https://creativecommons.org/licenses/by-nc-sa/4.0/ 


\title{
Les arts en France autour de 1400. Création artistique, questions iconographiques
}

\author{
Daniel Russo
}

1 Durant le printemps et l'été 2004, cinq grandes expositions ont montré la très grande richesse des arts en France, sous le règne de Charles VI (1368-1422), roi de 1380 à 1422, et d'Isabeau de Bavière (1371-1435), reine de 1385 à 1435. Une forte insistance fut mise sur le foyer parisien (Paris 1400. Les arts sous Charles VI, musée du Louvre, Paris, 22 mars-12 juillet, sous le commissariat d'Élisabeth TABURET-DELAHAYE), mais aussi, et ce fut une grande originalité, sur les principaux foyers situés dans les "apanages", c'est-à-dire les territoires sous le contrôle des "princes des fleurs de lys", oncles et frère du roi : L'art à la cour de Bourgogne. Le mécénat de Philippe le Hardi et de Jean sans Peur, 1364-1419, musée des Beaux-Arts, Dijon, 28 mai-15 septembre 2004, sous le commissariat de Sophie JUGIE et de Stephen N. FLIEGEL; Les Très Riches Heures du duc de Berry et l'enluminure en France au début $d u X^{e} V^{e}$ siècle, musée Condé, Château de Chantilly, 31 mars-2 août 2004, sous la responsabilité d'Emmanuelle toulet et de Patricia STIRNEMANn; Une fondation disparue de Jean de France, duc de Berry. La Sainte-Chapelle de Bourges, musée du Berry, Bourges, 26 juin-15 septembre 2004, sous le commissariat de Béatrice CHANCEL-BARDELOT et de Clémence RAYNAUD ; enfin, Louis d'Orléans et Valentine Visconti, Château et musée de Blois, 26 juin-12 septembre 2004, sous le commissariat de Thierry CRÉPIN-LEBLOND, assisté de Pierre-Gilles GIRAuLt. Dans le cadre des "Rencontres de l'École du Louvre", un colloque international fut organisé sur La création artistique en France autour de 1400, les 7-8 juillet à Paris, les 9-10 juillet à Dijon, reprenant les questions de la commande artistique, des modèles, des emblèmes et des échanges, des artistes, des ateliers et des chantiers, des formes et de l'iconographie. Nous résumerons la matière très dense des expositions et des débats en quelques points de synthèse.

Une affaire de générations

2 À travers tous les objets ainsi réunis, par-delà la diversité des situations géographiques et politiques, il s'agissait de comprendre, en un même mouvement, toute la création de 
ces années à la charnière entre la fin du $\mathrm{XIV}^{\mathrm{e}}$ et les deux premières décennies du XV $\mathrm{XV}^{\mathrm{e}}$ siècle. Dans l'espace, et du fait de la constitution de véritables états indépendants, sous l'autorité d'un prince de sang royal et de la maison de Valois, les réalisations artistiques auraient pu être très différentes. Ce ne fut pas le cas, au contraire: s'ils ne dissimulèrent pas les jalousies et les rivalités féroces, les liens de parenté entre les princes, le puissant attrait toujours exercé par la ville de Paris, l'émulation du goût et le plaisir de posséder, tous ces facteurs contribuèrent à rendre unique ce moment artistique. Trois générations se partagèrent de la sorte les commandes et les ateliers chargés de leur exécution: d'abord, celle du roi Charles V, dit le Sage, roi de 1364 à 1380, et de sa femme Jeanne de Bourbon, avec la montée en puissance et le mécénat fastueux de ses frères, Louis $1^{\text {er }}$ d'Anjou (1339-1384), Jean, duc de Berry (1340-1416), Philippe II dit le Hardi, duc de Bourgogne (1342-1404); ensuite, celle du roi Charles VI, avec son frère puîné, Louis $1^{\text {er }}$ d'Orléans (1372-1407), et ses cousins Jean sans Peur (1371-1419) et Louis II d'Anjou (1377-1417); enfin, celle du dauphin, Louis de Guyenne, puis après sa mort, du jeune Charles, futur Charles VII (1403-1461), roi de France à partir de 1422. Au plus fort des crises de régime (défaite devant les Anglais à la bataille d'Azincourt, en 1415 ; "honteux traité" de Troyes, en 1420) et des humiliations infligées au roi, tous les princes et leurs clientèles, surtout urbaines et plus encore parisiennes, ne cessèrent jamais leurs investissements dans la pierre, l'or, l'argent, l'améthyste ou l'émail. Car cela faisait partie intégrante de leur conception du pouvoir et de la qualité qu'ils souhaitaient imprimer à leur vie. Alors que les apanages créés par le roi Jean II le Bon (1319-1364, roi de France à partir de 1350) pour ses fils, les frères du roi Charles V, montraient tous leurs effets pernicieux sur l'unité du royaume, jamais l'éclat des arts en France ne fut aussi grand.

Le renouveau de la peinture

3 Dans Paris même, et grâce aux constructions princières, hôtels, maisons, l'architecture flamboyante fit ses débuts, timides au demeurant, par exemple dans le réseau utilisé pour les baies de la nef à l'intérieur de la Sainte-Chapelle, à Vincennes, ou dans la même forme de réseau employé pour les baies de la chapelle Notre-Dame-de-BonneNouvelle, vers 1400-1410. En matière d'architecture civile, Robert de Helbuterne dota le grand escalier de l'hôtel parisien du duc de Bourgogne, de 1409 à 1411, d'une voûte sur laquelle les ogives se changeaient en végétaux naturalistes et emblématiques. La façade de la maison édifiée par Nicolas Flamel, en 1407, était parée d'un décor gravé qui suivait les nouvelles tendances apparues dans la sculpture et la peinture. Ces décors flamboyants furent expérimentés à plein dans les constructions décidées par les princes en leurs états, en Bourgogne, sur le chantier de la chartreuse de Champmol, à Dijon, dont l'acte de fondation fut signée par Philippe le Hardi en 1385, en Berry, sur le chantier de la Sainte-Chapelle, à Bourges, ouvert en 1391-1392.

Mais l'image peinte dans les livres, à destination privée, parfois à forte charge politique, retint davantage l'attention de cette clientèle illustre. La mode était aux livres d'heures et aux missels, suivant qu'on était laïc ou clerc, richement enluminés et armoriés avec soin. Les grands ateliers étaient à Paris, et l'on s'adressait à eux en priorité. Les maîtres renommés n'étaient pas tous français, car les étrangers affluaient en ville. Parmi ceux-ci, les néerlandais formaient le contingent sans doute le plus nombreux et le mieux organisé. En 1400, Philippe le Hardi intervint dans une affaire de litige qui mettait en évidence les relations de son peintre attitré, Jean Malouel (avant 1370-1415), originaire de Nimègue, alors à Paris en apprentissage chez l'orfèvre Alebret de Bolure, néerlandais, avec deux de ses neveux, deux des fameux frères de Limbourg. 
La présence des Italiens était aussi clairement attestée : tel le très actif Pietro Sacco de Vérone, qui joua un grand rôle dans le commerce du livre à Paris, entre 1397 et 1423 , tout en s'occupant durant un temps des ouvrages destinés au duc Jean de Berry. Un autre italien, le Maître des Initiales de Bruxelles, obtint la faveur des bibliophiles les plus riches, dont Jean de Berry, Charles Le Noble, roi de Navarre, et l'anti-pape Benoît XIII (1394-1417) : spécialisé dans l'illustration du livre d'heures, il poursuivit, dans ses décors, ses architectures et ses figures, le style courtois du bolonais Niccolo di Giacomo, (actif dans le dernier quart du XIVe siècle), comme sur le feuillet 20 des Heures à l'usage de Paris, vers 1406-1407 (auj. British Library, Londres, Add. 29433). La fortune de ces maîtres était facilitée par le goût du livre enluminé, très diffusé dans les milieux proches de la cour royale et des princes, puissants du jour ou plus modestes officiers. Parmi d'autres, Béraud III d'Auvergne, comte de Clermont (mort en 1426), un familier du duc de Bourbon, s'adressa au Maître de Boucicaut pour faire illustrer son exemplaire personnel du Livre des propriétés des choses de Barthélemy l'Anglais, vers 1415 (auj. ms. fr. 9141, Bibliothèque de France, Paris) et le marquer, au feuillet 55, de ses armoiries.

Le goût pour le bel objet

D'extraction plus modeste, Jean de Roussay (mort vers 1418) fut aussi, à sa manière, un client assidu des échoppes parisiennes. Parfait exemple de ces gentilshommes opportunistes de l'époque, il s'assura une solide fortune en servant, avec prudence et habileté, le roi Charles VI, puis Louis d'Orléans, la reine Isabeau, Jean sans Peur, Louis de Guyenne. Bénéficiant de nombreux cadeaux, il intervint dans des commandes d'objets d'orfèvrerie. Ses généreux protecteurs agirent de même, faisant exécuter pour leur compte personnel ou pour les offrir, toutes sortes de bijoux, de broderies, de "joyaux", mentionnés dans leurs inventaires. Philippe le Hardi avait coutume de passer commande à Paris, auprès des orfèvres Hennequin du Vivier et Hermann Ruissel. Sa femme, Marguerite de Flandre, y fit réaliser un joyau de grand prix, le Calvaire de Matthias Corvin ou d'Esztergom, conservé dans le trésor de la cathédrale, pour l'offrir en cadeau d'étrennes à son mari le jour de l'an 1403. De même, la reine Isabeau de Bavière commanda une Image de Notre Dame, dite Cheval d'or, aujourd'hui dans le trésor d'Altötting, afin d'en faire cadeau au roi Charles VI pour les étrennes de 1405. On y voit la Vierge tenant l'Enfant Jésus et trônant sous un berceau de feuillage orné de pierres précieuses, de fleurs émaillées et de perles, tandis que deux anges portent au-dessus de sa tête la couronne de la Reine des cieux. Devant la treille sont agenouillés Charles VI et un chevalier portant le heaume royal. Par-derrière le roi se tient le tigre, son emblème, tandis qu'au niveau inférieur de l'édicule en forme de petit théâtre un valet attend, tenant en bride, aujourd'hui disparue, un destrier qui hennit d'impatience. Dans cet objet d'or émaillé et ciselé, d'argent doré pour le niveau du bas, incrusté de saphirs, de rubis et de perles, l'univers temporel de la cour est subordonné à l'apparition céleste de la Vierge à l'Enfant. Même hiérarchisés, les deux mondes sont pourtant rapprochés l'un de l'autre, comme si, désormais, l'on avait voulu oublier les vieux codes iconographiques et préparer la voie à la nouvelle image de cour, précieuse et privée. Le goût pour les objets émaillés dorés, en ronde-bosse, caractérise toute une société, riche et avisée, qui annonce celle des cours européennes de la Renaissance.

Bibliographie

6 Paris 1400. Les arts sous Charles VI, catalogue d'exposition, Fayard-Réunion des musées nationaux, Paris, 2004 ; Les Très Riches heures du duc de Berry et l'enluminure en France au début du XVe siècle, catalogue d'exposition, Somogy, Paris, 2004; L'art à la cour de Bourgogne. Le mécénat de Philippe le Hardi et de Jean sans Peur (1364-1419), catalogue 
d'exposition, Réunion des musées nationaux, Paris, 2004 ; Une fondation disparue de Jean de France, duc de Berry. La Sainte-Chapelle de Bourges, catalogue d'exposition, Somogy, Paris, 2004 ; Louis d'Orléans et Valentine Visconti. Mécénat et politique autour de 1400, petit journal de l'exposition, Château et musées de Blois, 2004; E. Kovacs, L'âge d'or de l'orfêvrerie parisienne au temps des princes de Valois, éditions Faton, Dijon, 2004.

INDEX

Mots-clés : peinture, objet, iconographie 